\title{
$\Omega$
}

Sandy Sutter ${ }^{1}$, Sharon Mitchell'1 ${ }^{1}$ Ernst Eber ${ }^{2}$, Gunilla Hedlin ${ }^{3}$, Fabio Midulla ${ }^{4}$,

${ }^{1}$ European Respiratory Society, Lausanne, Switzerland. ${ }^{2}$ Paediatric Dept, Medical University of Graz, Graz, Austria. ${ }^{3}$ Dept of Women's and Children's Health, Karolinska Institutet, Stockholm, Sweden. ${ }^{4}$ Cystic fibrosis, University of Rome, Rome, Italy. ${ }^{5}$ Royal Hospital for Sick Children, Glasgow, UK. ${ }^{6}$ Paediatrics Dept, Addenbrookes Hospital, Cambridge, UK. ${ }^{7}$ Dept of Paediatrics, Marienhospital, Wesel, Germany.

\section{Paediatric HERMES: European accreditation of training centres in paediatric respiratory medicine}

\section{Medical training accreditation}

Some form of medical training accreditation is used in over 110 countries worldwide [1]. Although accreditation criteria and processes vary considerably depending on regional medical training structures and national regulations, various studies suggest that the accreditation of training programmes has a positive impact on trainees' performance in assessments [2, 3]. Thus, accreditation is an important tool for promoting high-quality training and medical care.

The development of related sub-specialty training accreditation criteria is, therefore, part of the overall European Respiratory Society (ERS) strategy to develop and offer assessment and training in respiratory medicine sub-specialties.

The benefit of standard settings, such as accreditation criteria for postgraduate medical training has already been discussed at length in previous publications [4-6]. The aim here is not to explore this again, but to provide readers with an overview of the method used to define accreditation criteria for paediatric respiratory medicine and to share preliminary findings on training organisation and training centre accreditation for this sub-specialty in Europe.
Following the development of the Adult and Paediatric Respiratory Medicine Curricula $[7,8]$ and examinations, the ERS leadership decided to further develop assessment tools and propose the accreditation criteria for adult respiratory medicine $[9,10]$. This was initially published in 2009 and was revised in 2015. Accreditation criteria for paediatric respiratory medicine now follow. Initial drafting started in late 2014 with the document being finalised at the beginning of 2016.

There are currently nine HERMES (Harmonised Education in Respiratory Medicine for European Specialists) projects (adult respiratory medicine, paediatric respiratory medicine, thoracic oncology, respiratory physiotherapy, respiratory infections, thoracic surgery, spirometry, respiratory critical care and respiratory sleep medicine), each at different phases of development. It is not yet possible to predict if all nine focus areas will develop training centre accreditation criteria and, where criteria are developed, whether a full centre accreditation will be set up. Needs are thoroughly assessed on a regular basis to ensure the best possible support is provided within the ERS remit for specialty training and assessment.
Cite as: Sutter S, Mitchell S, Eber E, et al. Paediatric HERMES: European accreditation of training centres in paediatric respiratory medicine. Breathe 2016; 12: 105-110.

This article has been revised according to the erratum published in the September 2016 issue of Breathe. 


\section{Understanding paediatric respiratory medicine in Europe}

In October 2013, the ERS conducted an initial survey aimed at providing a better understanding of the structure of paediatric respiratory medicine training and accreditation processes in place for paediatric respiratory medicine training centres across Europe. The results showed that paediatric respiratory medicine is not yet recognised as a sub-specialty in all European countries.

In order to confirm and update the information gathered in the initial survey, European members of the ERS Paediatric Assembly were contacted in August 2015. They were asked specific questions pertinent to the organisation of paediatric respiratory medicine training and accreditation in their respective countries.

Of the 640 professionals contacted, 102 participants representing 27 countries responded (figure 1). The highest response rates came from Italy (14 respondents), the UK (12 respondents) and Spain (10 respondents). This represents perception of a fraction of the paediatric respiratory medical specialist population as the information provided has not been validated with official sources. Therefore, the data below needs to be interpreted with caution.

For the most part, at the time of the survey respondents mainly defined themselves as paediatricians specialised in paediatric respiratory medicine (59 respondents) or general paediatricians with a special interest in paediatric respiratory medicine (16 respondents). A few trainees in paediatric respiratory medicine (eight respondents) took part as well as paediatricians, either in an academic position with limited clinical practice (six respondents) or specialised in a field other than respiratory (one respondent). The participants who defined themselves in the other category (12 respondents) included PhD students, retired paediatricians or paediatricians who had partial training in paediatric respiratory medicine at the time of survey.

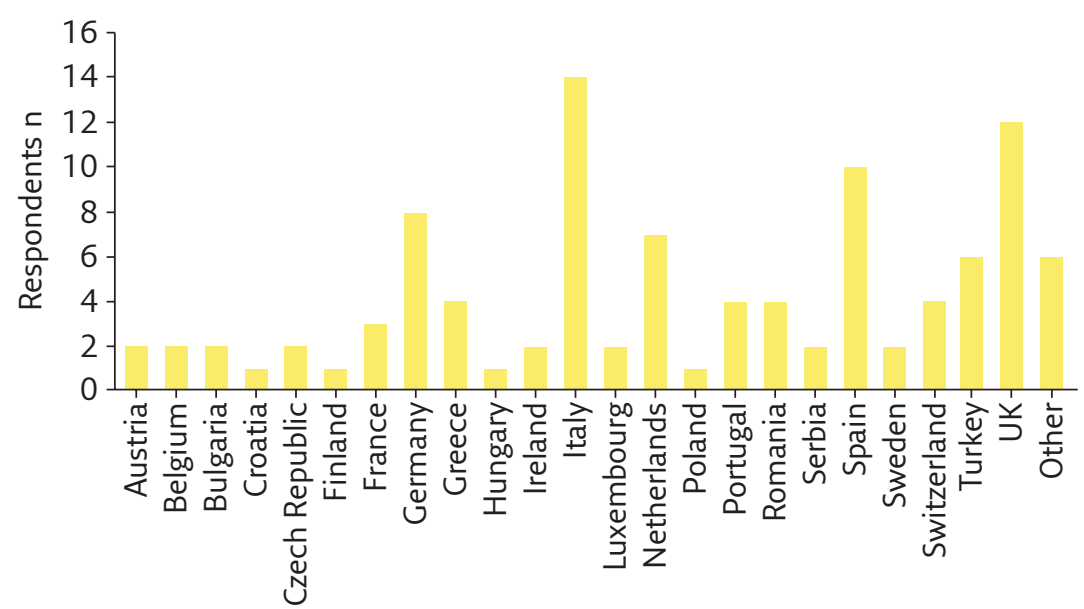

Figure 1 Country representation.
$70 \%$ of the respondents indicated they played a role in a paediatric respiratory medicine training programme, while $30 \%$ did not. The majority of respondents involved in their centre's paediatric respiratory medicine training programme indicated they worked as clinical supervisors (56\%) at the time of survey, followed by teachers (48\%) and educational supervisors (42\%). Trainees and programme directors were also represented in the surveyed population.

$67 \%$ of the respondents stated that, to their knowledge, there is a paediatric respiratory training programme (whether formal or informal) in place at their institution. To the question "Is there an official national training programme in paediatric respiratory medicine in your country?" 55\% responded that there was no official programme, $41 \%$ replied there was and $4 \%$ answered that they did not know. $55 \%$ of respondents also stated that to their knowledge there was no nationally recognised paediatric respiratory medicine curriculum in their country. Although further information was collected on the structure of existing formal and informal training programmes and centres delivering these programmes, this data would need to be validated with training centres and national authorities before results could be published.

\section{Paediatric respiratory medicine specialists versus paediatricians with a special interest}

Regarding the recognition of paediatric respiratory specialists, the majority of respondents (62\%) advised that a distinction is made in their country between paediatric respiratory specialists and general paediatricians with a special interest in respiratory medicine. Over half of the surveyed population (54\%) stated that the paediatric respiratory sub-speciality is officially recognised in their countries, and that general paediatricians with a special interest is not (59\%).

The duration of officially recognised paediatric respiratory medicine training was reported to last 2-3 years (figure 2), following typical general paediatrician training of 4-5 years.

The majority of respondents (93\%) felt that trainees would benefit from standardised training and certification for sub-specialty training in paediatric respiratory medicine across Europe.

\section{Paediatric respiratory medicine training accreditation in Europe}

To the question "In your country, is there an official accreditation process for paediatric respiratory 
medicine training centres?" $48 \%$ of respondents stated that no official accreditation process exists, $41 \%$ answered that there is an accreditation process and $11 \%$ did not know. The information gathered for countries where official accreditation processes exist suggests that the authority responsible for providing training accreditation is not necessarily an accreditation body that is independent from the training centres.

Training of paediatricians with a special interest in paediatric respiratory medicine, as a comparison, was seldom accredited (23\% of respondents reported that an accreditation process exists in that case).

In countries where an official accreditation process is in place for paediatric respiratory medicine training centres, collected data suggest that the training centres undergo the accreditation process every $3-5$ years (figure 3 ).

In most cases, respondents indicated that the accreditation process entails either obligatory $(57 \%)$ or voluntary (29\%) self-reporting by the centres. Site visits, however, do not seem to be necessarily performed. A few respondents advised that although a site visit was initially part of the national accreditation process this was abolished.

\section{Methods}

The method used to define and validate the paediatric accreditation criteria and links between the paediatric and revised adult accreditation criteria are presented below, as both documents were prepared in parallel.

\section{Timeline}

In June 2014, a working group of six expert paediatricians were mandated to define the paediatric respiratory medicine criteria. The working group had its first meeting in September 2014 during the ERS international Congress (Munich, Germany) to agree on the criteria definition process. It was decided that rather than having long face-to-face workshops, the group would discuss the criteria in regular 2 -h teleconferences taking place every 4 weeks, allowing sufficient time for members to prepare and reflect on the criteria.

In order to finalise the first draft of the criteria document, eight teleconferences were organised between October 2014 and June 2015.

Through summer 2015, the criteria were validated by a wider group of experts and the previously mentioned survey on paediatric respiratory medicine training structure and accreditation in Europe was conducted.

The paediatric respiratory medicine working group met again during the ERS International Congress in Amsterdam (the Netherlands) in 2015 to discuss the next steps, the survey results and the criteria publication plan. During this meeting,

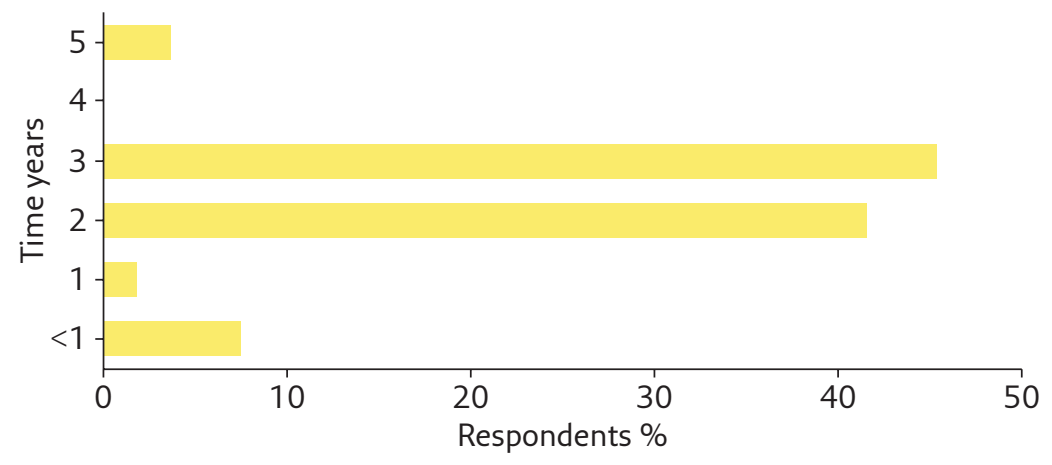

Figure 2 Duration of officially recognised paediatric respiratory medicine training.

the working group agreed it would make sense to wait until the updated criteria document for adults was finalised in order to incorporate the latest changes suggested by medical education advisors and the European Lung Foundation. Consequently, the last two teleconferences to finalise the criteria document were held in February 2016.

\section{Criteria definition}

In order to keep a degree of consistency between the adult and paediatric documents, the paediatric working group used the Adult Accreditation Criteria published in 2009 as a basis to define the criteria for paediatric respiratory medicine [9].

As per the adult criteria, and following World Federation for Medical Education Global Standards for Quality Improvement [11], two criteria levels were defined [12]. 1) Basic standards criteria: the standards a centre must meet to provide a minimum level of support to trainee and training facilities to ensure adequate training. 2) Quality development criteria: additional standards for

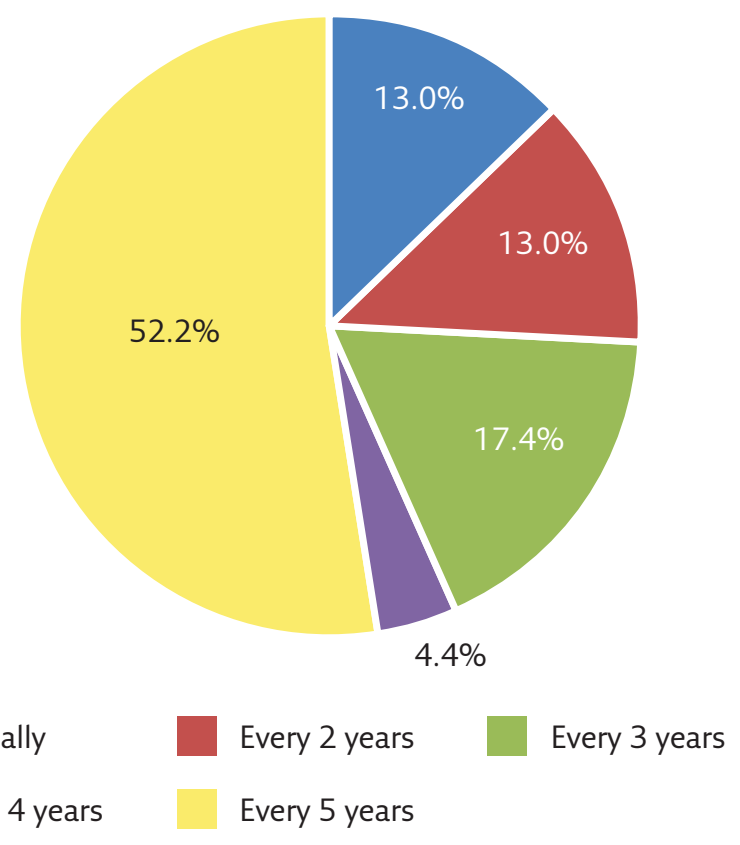

Figure 3 Paediatric respiratory medicine training centre accreditation cycle duration. 
excellence, in accordance with international consensus regarding best practice for postgraduate medical education [11].

As a first step, the working group carefully looked at each criterion, defining whether: 1) the criterion applied to paediatric respiratory medicine; 2) the criterion needed complete revision, minor rephrasing or deletion from the document; and 3) the criterion categorisation (i.e. basic standards or quality development) follows best practice in paediatric respiratory medicine

The changes proposed by the paediatric working group that might also be applicable to adult respiratory medicine were fed back in the adult criteria revision process, which proceeded in parallel and was led by the ERS/European Board for Accreditation in Pneumology (EBAP) Accreditation Committee. Similarly, amendments made to the adult criteria relevant to paediatric respiratory medicine, including European Lung Foundation suggestions for patient involvement, were forwarded for consideration by the paediatric working group (figure 4).

Throughout summer and autumn 2015, the Accreditation Committee consulted with three medical education specialists in order to improve the accreditation documents. More specifically, chapter 4 (pertaining to the content of educational experience) was thoroughly reviewed, resulting in a criterion outlining the importance of a positive learning environment being added and the list of example educational methods being amended.

As for the assessment methods and toolbox, it was initially the Accreditation Committee's intention to expand and further develop the whole section. After discussions with the medical education specialists and within the committee, it was decided to keep the section and the assessment toolbox concise. An appendix including details for each assessment method [13], linked back to the levels of assessments of MILLER [14], was added to the document. ERS intends to develop, in the mid- to long-term future, assessment tools and templates linked to the various ERS curricula to help training centres standardise assessment processes.

Both criteria documents also benefited from the addition of criteria linked to the involvement of patients $[10,15,16]$ following recommendations and discussions with the European Lung Foundation.

\section{Criteria validation process}

As a second step, the criteria were sent to a larger group of experts for validation, which consisted of members of the ERS Paediatric Examination Committee and Paediatric Assembly, Paediatric National Respondents, members of the Long Range Planning Committee and EBAP paediatric reviewers, as well as the ERS/EBAP Accreditation Committee.

37 experts responded from the 98 survey recipients (38\% response rate). For each criterion, the experts were asked the following questions: 1 ) is this a relevant criterion for paediatric respiratory medicine training centre accreditation?; and 2) do you agree that this is a criterion for quality development or basic standard?

The response options ranged from 1 (strongly disagree) to 5 (strongly agree). Each option was given a weight: $1=$ =strongly disagree; $2=$ disagree; $3=$ neither agree nor disagree; 4=agree; and $5=$ strongly agree. Thus, a weighted average could be calculated based on the weight assigned to each answer choice.

$$
\frac{\mathrm{x}_{1} \mathrm{w}_{1}+\mathrm{x}_{2} \mathrm{w}_{2}+\mathrm{x}_{3} \mathrm{w}_{3} \ldots \mathrm{x}_{\mathrm{n}} \mathrm{w}_{\mathrm{n}}}{\text { Total }}
$$

The response to the validation process was positive overall; respondents either agreed or strongly agreed that $90 \%$ of the criteria were relevant, and agreed or strongly agreed with the criteria categorisation for $83 \%$ of the criteria.

a)

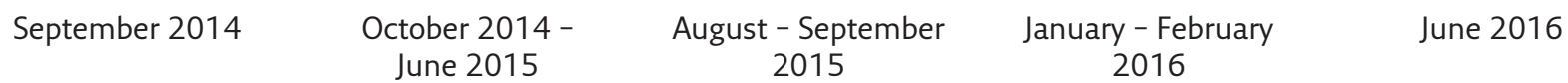

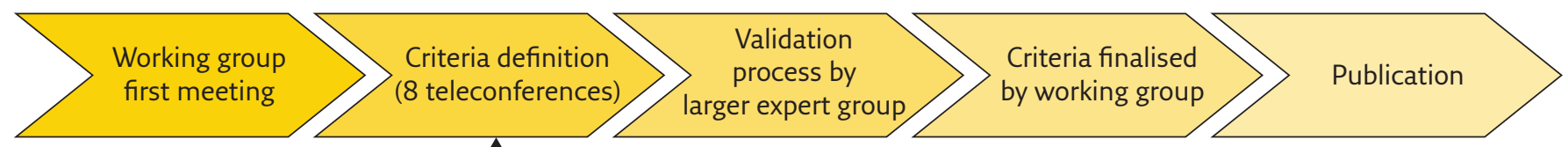

Adult and paediatric "content of educational experience" section checked by eductionalists

b)

Validation process by larger expert group
Criteria finalised by Accreditation Committee

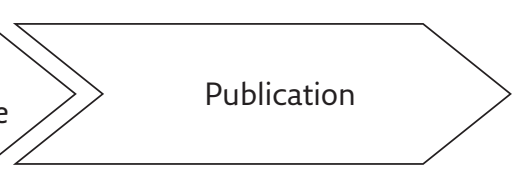

Figure 4 a) Paediatric and b) adult accreditation criteria. 


\section{Criteria document for publication}

Results of the validation survey were shared with the working group in autumn 2015 and were discussed during the two teleconferences in February 2016.

During this thorough second review process, the working group carefully looked at each criterion again, taking into account not only the weighted average but also the specific comments made by respondents when relevant. Further amendments were made to the criteria, incorporating the experts' opinions, resulting mainly in changes in the criteria categorisation.

Finally, the criteria document was circulated again to the working group as well as to the ERS/ EBAP Accreditation Committee co-chairs for one final review.

\section{Next steps}

\section{Accreditation process for paediatric respiratory medicine}

At this stage and considering the preliminary survey results, the feasibility of developing a sustainable ERS/EBAP European accreditation process for paediatric respiratory medicine needs further investigation. If the ERS and EBAP leadership decide to implement the European accreditation process for paediatric respiratory medicine, it will be necessary to determine whether a similar process to that of the accreditation process for adult respiratory medicine is applicable. A pilot phase will be needed to ensure appropriateness of the criteria and workability of related forms and supporting documents. A second important consideration will be to assess how many countries formally recognise paediatric respiratory medicine as a sub-specialty to paediatric medicine and how many nationally accredited training centres or programmes exist. This will have important implications to assess the need for an international process for accreditation.

\section{Development of assessment tools}

During the accreditation of three European centres in adult respiratory medicine, it was noticed that although training centres conduct formative assessments and provide feedback to trainees, no formalised process is in place. Therefore, it is the intention of ERS to develop, under the remit of the Assessment Committee, a series of assessment forms and guides to help training centres conduct formative assessments. These documents will be linked to the different HERMES curricula and will be established with the help of medical education specialists, ensuring best practice is followed.

\section{Conclusion}

The Training Centre Accreditation Criteria for paediatric respiratory medicine is only a small step on the path leading to quality postgraduate medical education, but it is unquestionably an important one. The ERS Education Council and EBAP leadership hope that the proposed standards for education outlined within both the adult and paediatric accreditation criteria documents will be favourably considered by training centres across Europe and entice directors, supervisors and faculty members to further improve the teaching and assessment methods within their centres.

\section{Acknowledgements}

We wish to thank Griet Peeraer and Erik Driessen (University of Maastricht, Maastricht, Germany) for their valuable comments on the section pertinent to the content of educational experience. We also wish to thank the members of the Accreditation Committee (G. Rohde, D. Stoz, J. Verbraecken, O. Karg and S. Skoczynski) for taking on board the suggestions from the paediatric working group and for their support in developing the paediatric accreditation criteria document. The following experts wrote the original accreditation criteria document for adult respiratory medicine, which was used as a basis to structure the paediatric accreditation document: R. Loddenkemper, T. Séverin, S. Mitchell, A. Belevskiy, A. Chuchalin, S. de Hosson, G. Di Maria, S. Hartl, I. Horvath, C. Leroyer, J-L. Noel, B. Nybo, G. Phillips, R. Stevenson, M. Zach and P. Palange.

\section{Supplementary material}

The Paediatirc HERMES: criteria for accreditation of ERS European training centres in paediatric respiratory medicine is available as supplementary material from breathe.ersjournals.com.

\section{Conflict of interest}

S. Sutter, S. Mitchell and A. Niculescu are employees of the European Respiratory Society. 


\section{References}

1. Foundation of Advancement of International Medical Education and Research (FAIMER). Directory of organisation that recognise/accredit medical schools (DORA). http:// faimer.org/resources/dora/index.html. Date last accessed: December 14, 2015. Date last updated: February 5, 2016

2. Van Zanten M. The association between medical education accreditation and examination performance of internationally educated physicians seeking certification in the United States. Perspect Med Educ 2015; 4: 142-145.

3. Van Zanten M, McKinley D, Durante I, et al. Medical education accreditation in Mexico and the Philippines: impact on student outcomes. Med Educ 2012; 46: 586-592.

4. Mitchell S, Bloch KE, Butienne I, et al. "Education is the passport to the future": enabling today's medical teachers to prepare tomorrow's respiratory health practitioners'. Eur Respir J 2014; 44: 578-584.

5. Mitchell S, Simonds A, Andreas S, et al. Introducing a core curriculum for respiratory sleep practitioners. Breathe 2015 11: 51-56.

6. Lilley P, Harden R. Standards in medical education. Med Teach 2003; 25: 349-351.

7. Loddenkemper R, Haslam PL, Séverin T, et al. European Curriculum Recommendations for Training in Adult Respiratory Medicine. Breathe 2008; 5: 80-93.

8. Gappa M, Noël JL, Séverin T, et al. Paediatric HERMES: European Curriculum Recommendations for Training in Paediatric Respiratory Medicine. Breathe 2010; 7: 72-117.
9. Loddenkemper R, Séverin T, Mitchell S, et al. Adult HERMES: criteria for accreditation of ERS European training centres in adult respiratory medicine. Breathe 2010; 7: 170-188.

10. Sutter S, Mitchell S, Verbraecken J, et al. HERMES: European Accreditation of Training Centres in Adult Respiratory Medicine criteria validation and revision. Breathe 2016; 12: 11-17.

11. van Niekerk DV, Christensen L, Karle $\mathrm{H}$, et al. WFME Global Standards in Medical Education: status and perspectives following the 2003 WFME World Conference. Med Educ 2003; 37: 1050-1054.

12. Sutter S, Stolz D, Rohde G, et al. ERS/EBAP European Accreditation of Training Centres in Adult Respiratory Medicine: how could it benefit your centre? Breathe 2015; 11: 183-185.

13. Amin Z, Seng CY, Eng KU. Practical Guide to Medical Student Assessment. Singapore, World Scientific Publishig Co Pte Ltd, 2006.

14. Miller GE. The assessment of clinical skills/competence/ performance. Acad Med 1990; 65: Suppl. 9, 863-8S7.

15. Hasman A, Coulter A, Askham J. Education for partnership: developments in Medical education. Oxford, Picker Institute Europe, 2006

16. General Medical Council. Patient and public involvement in undergraduate medical education. Advice supplement to Tomorrows Doctors. www.gmc-uk.org/ Patient and public involvement in undergraduate medical_education___guidance_under_review_0815. pdf_56438926.pdf Date last accessed: December 16, 2015. 